\title{
Evidências científicas sobre a realização do tratamento endodôntico em sessão única
}

\author{
Scientific evidence on the performance of endodontic treatment in single session \\ Evidencia científica sobre la realización del tratamiento de endodoncia en una sola sesión
}

Recebido: 24/06/2021 | Revisado: 30/06/2021 | Aceito: 04/07/2021 | Publicado: 15/07/2021

\author{
Ianara Vitória Souza de Lucena \\ ORCID: https://orcid.org/0000-0001-7030-8498 \\ Faculdade Nova Esperança, Brasil \\ E-mail: ianaralucena@gmail.com \\ Herrison Félix Valeriano da Silva \\ ORCID: https://orcid.org/0000-0001-6714-3151 \\ Universidade Federal da Paraíba, Brasil \\ E-mail: Herrison.felix.vds@gmail.com \\ Fernanda Clotilde Mariz Suassuna \\ ORCID: https://orcid.org/0000-0001-5846-288X \\ Faculdade Nova Esperança, Brasil \\ E-mail: fernandacosta3@ hotmail.com \\ Luiza de Almeida Souto Montenegro \\ ORCID: https://orcid.org/0000-0002-5678-0144 \\ Faculdade Nova Esperança, Brasil \\ E-mail: luizasmontenegro@gmail.com \\ Thauany Vasconcelos Soares da Silva \\ ORCID: https://orcid.org/0000-0002-6831-9224 \\ Universidade Federal da Paraíba, Brasil \\ E-mail: vasconcelosthauany@gmail.com \\ Manoel Pereira de Lima \\ ORCID: https://orcid.org/0000-0002-5605-0651 \\ Universidade Federal da Paraíba, Brasil \\ E-mail: Manoel_lima18@yahoo.com.br \\ Maria Eduarda de Araujo Cruz \\ ORCID: https://orcid.org/0000-0001-8876-8249 \\ Faculdade Nova Esperança, Brasil \\ E-mail: eduardaaraujo207@gmail.com \\ Bárbara Jéssica de Assunção Costa \\ ORCID: https://orcid.org/0000-0001-7496-0512 \\ Universidade Estadual de Campinas, Brasil \\ E-mail: barbaraassuncao@outlook.com \\ Jussara da Silva Barbosa \\ ORCID: https://orcid.org/0000-0001-6123-5266 \\ Faculdade Nova Esperança, Brasil \\ E-mail: barbosajsara@gmail.com
}

\begin{abstract}
Resumo
Esta revisão integrativa objetivou-se a comparar o tratamento endodôntico em uma única sessão com aquele realizado em múltiplas sessões, buscando evidências científicas a respeito da redução de complicações pós-operatórias como dor, retratamento, diminuição de bactérias e efetividade do tratamento endodôntico em sessão única. O estudo foi realizado por meio de um levantamento bibliográfico nas bases de dados Pubmed e SciELO com manuscritos publicados entre os anos de 2017 e 2021, utilizando as seguintes palavras-chaves: "Endodontia"; "Tratamento do Canal Radicular"; "Sessão única”, com o auxílio do operador booleano "AND”. Um total de 123 artigos foram encontrados, onde 39 foram avaliados com base nos critérios de inclusão: Estudos que avaliaram o tratamento endodôntico em sessão única, estudos publicados nos últimos 05 anos, e como critérios de exclusão: Artigos não relacionados ao tema, além de trabalhos de conclusão de cursos, tese e dissertações, resultando em 5 artigos utilizados para esta revisão. A literatura mostra que o tratamento do canal radicular em sessão única, realizada com uma boa técnica, traz resultados eficientes, porém, alguns estudos apontaram resultados conflitantes, A análise da literatura apresenta que a abordagem em sessão única apresenta resultados efetivos, entretanto, sabe-se que as técnicas são operador-dependente. Em elementos com alto índice de infecção os resultados são conflitantes, com algumas fontes apresentando resultados efetivos com o tratamento em sessão única, independente do estado do elemento abordado, e outras apresentando vantagens em uma abordagem com múltiplas sessões, quando apresenta conteúdo séptico. Dessa forma, novos estudos clínicos são necessários para comparar as duas técnicas, para determinar indicações claras para cada uma delas.
\end{abstract}

Palavras-chave: Endodontia; Tratamento do canal radicular; Padrões de prática odontológica. 


\begin{abstract}
This integrative review aimed to compare endodontic treatment in a single session with that carried out in multiple sessions, seeking scientific evidence regarding the reduction of postoperative complications such as pain, retreatment, reduction of bacteria and effectiveness of endodontic treatment in a single session. The study was carried out through a bibliographic survey in Pubmed and SciELO databases with manuscripts published between 2017 and 2021, using the following keywords: "Endodontics"; "Treatment of the Root Canal"; "Single session", with the help of the Boolean operator "AND". A total of 123 articles were found, where 39 were evaluated based on the inclusion criteria: Studies that evaluated endodontic treatment in a single session, studies published in the last 05 years, and as exclusion criteria: Articles not related to the topic, in addition to course completion papers, thesis and dissertations, resulting in 5 articles used for this review. The literature shows that the treatment of the root canal in a single session, performed with a good technique, brings efficient results, however, some studies have shown conflicting results. if that the techniques are operator-dependent. In elements with a high infection rate, the results are conflicting, with some sources presenting effective results with the treatment in a single session, regardless of the state of the approached element, and others presenting advantages in a multiple session approach, when it presents septic content. Thus, further clinical studies are needed to compare the two techniques, to determine clear indications for each of them.
\end{abstract}

Keywords: Endodontics; Root canal treatment; Standards of dental practice.

\title{
Resumen
}

Esta revisión integradora tuvo como objetivo comparar el tratamiento endodóntico en una sola sesión con el realizado en múltiples sesiones, buscando evidencia científica sobre la reducción de complicaciones postoperatorias como dolor, retratamiento, reducción de bacterias y efectividad del tratamiento endodóntico en una sola sesión. El estudio se realizó a través de una encuesta bibliográfica en las bases de datos Pubmed y SciELO con manuscritos publicados entre 2017 y 2021, utilizando las siguientes palabras clave: "Endodoncia"; "Tratamiento del conducto radicular"; "Sesión única", con la ayuda del operador booleano "Y". Se encontraron un total de 123 artículos, donde se evaluaron 39 en base a los criterios de inclusión: Estudios que evaluaron el tratamiento endodóntico en una sola sesión, estudios publicados en los últimos 05 años, y como criterio de exclusión: Artículos no relacionados con el tema, además a los trabajos de finalización del curso, tesis y disertaciones, lo que resultó en 5 artículos utilizados para esta revisión. La literatura muestra que el tratamiento del conducto radicular en una sola sesión, realizado con una buena técnica, trae resultados eficientes, sin embargo, algunos estudios han mostrado resultados contradictorios, si es que las técnicas son dependientes del operador. En elementos con alta tasa de infección, los resultados son contradictorios, presentando algunas fuentes resultados efectivos con el tratamiento en una sola sesión, independientemente del estado del elemento abordado, y otras presentando ventajas en un abordaje de múltiples sesiones, cuando presenta séptica contenido. Por lo tanto, se necesitan más estudios clínicos para comparar las dos técnicas, para determinar indicaciones claras para cada una de ellas.

Palabras clave: Endodoncia; Tratamiento de conducto; Estándares de la práctica odontológica.

\section{Introdução}

Novas técnicas têm sido desenvolvidas dentro da endodontia com a finalidade de agilizar e facilitar o tratamento endodôntico. Para que a instrumentação dos canais radiculares ocorra de forma eficiente e segura, algumas etapas precisam ser executadas, como a limpeza, modelagem e obturação dos sistemas de canais radiculares (REF). O preparo químico mecânico (PQM) é fundamental para o sucesso da endodontia, pois ele tem como objetivo diminuir a infecção causada pelos microrganismos e dar forma aos canais radiculares desde o terço cervical até o ápice, propiciando uma melhor obturação dos canais radiculares (Wong, et al., 2014).

As limas manuais de aço inoxidável são utilizadas para fazer a limpeza e modelagem dos canais radiculares trazendo resultados bem-sucedidos. Contudo, a instrumentação manual com limas aço inoxidável ou NiTi exigem maior tempo clínico e apresenta um risco de perfuração e deformidade do canal radicular devido a sua rigidez (Boonchoo et al.,2020).

Sabendo disso, com o avançar dos estudos foram desenvolvidas limas com superelasticidade e com memória de forma feitas de liga M-Wire, que é uma liga especial de níquel-titânio (NiTi) criada com um inovador processo de tratamento térmico (Wei et al.,2017). Com o advento de tal liga, o tratamento dos canais radiculares aumentou sua taxa de sucesso em virtude das vantagens do uso da liga, tais como diminuição da força de ligação do instrumento à parede de dentina, resultando em uma menor fadiga cíclica e menor risco de fratura do instrumento, como também uma redução significativa do tempo clínico e posteriormente, surgiu o interesse para a utilização de tais instrumentos em dentes decíduos (Boonchoo et al.,2020). 
Com a introdução desses instrumentos, o processo de preparo mecânico do canal radicular tornou-se mais previsível no ambiente clínico. O movimento rotatório, introduzido no final dos anos 1980, é ainda empregado pela maioria dos sistemas de preparação mecânica no mercado (REF). É realizado por motores elétricos acionando limas NiTi em rotação total $\left(360^{\circ}\right)$ dentro do canal radicular. No entanto, novas técnicas mecanizadas têm sido propostas na tentativa de minimizar o risco de fratura dos instrumentos endodônticos, como o movimento alternado ou reciprocante, que também usa motores elétricos e contra-ângulos que acionam limas NiTi nos sentidos anti-horário e horário (Gavini et al.,2018).

Uma forma alternativa para o tratamento endodôntico foi desenvolvida permitindo a instrumentação e preparo do canal radicular com a utilização de apenas uma única lima, acarretando a diminuição do tempo de instrumentação dos canais em relação aos sistemas rotatórios de sequência completa, onde o profissional realiza todo o procedimento uma única sessão (Wei et al.,2017).

Recentemente, o tratamento endodôntico com uso de lima única ganhou maior aceitação e tal técnica vem sendo aplicada na prática clínica. Várias vantagens, incluindo a redução do tempo clínico com sessão única e a diminuição do risco de perfurações fizeram com que essa prática se tornasse mais concebível e conveniente (Berutti et al.,2012).

Apesar de todo o avanço tecnológico dos instrumentos endodônticos, algumas complicações no tratamento dos canais radiculares são frequentes, sendo a dor pós-operatória a principal delas. A ocorrência e a intensidade da dor após o tratamento endodôntico podem estar relacionadas com a utilização de vários instrumentos durante uma única sessão clínica, devido a extrusão de debris (Sun et al.,2018). Dessa forma é necessário ampliar o conhecimento a respeito da eficiência do tratamento endodôntico em apenas uma única sessão.

Esta revisão integrativa objetivou comparar o tratamento endodôntico em uma única sessão com aquele realizado em múltiplas sessões, buscando evidências científicas a respeito da redução de complicações pós-operatórias como dor, necessidade de retratamento, diminuição de bactérias e efetividade do tratamento endodôntico em sessão única.

\section{Metodologia}

A pesquisa consistiu em uma revisão integrativa, a qual foi realizada por meio de um levantamento bibliográfico, permitindo uma análise detalhada de vários estudos da literatura atual, correlacionando os resultados encontrados com a prática clínica com base em evidências científicas (Souza et al.,2010).

Esta revisão foi dividida em algumas etapas. Na primeira etapa foi realizado um levantamento bibliográfico nas seguintes bases de dados: Pubmed e SciELO. Foram utilizadas combinações das palavras-chave "Endodontia"; "Tratamento do Canal Radicular"; "Sessão única" (em inglês, espanhol e português), com o auxílio do operador booleano "AND”. Os critérios de inclusão: Estudos que avaliaram o tratamento endodôntico em sessão única, estudos publicados nos últimos 05 anos, e estudos publicados na íntegra nos idiomas português, espanhol e/ou inglês. Como critérios de exclusão: Artigos não relacionados ao tema, além de trabalhos de conclusão de cursos, tese e dissertações.

Para constituir a segunda etapa da presente pesquisa foi realizada a leitura dos títulos e resumos dos artigos pesquisados previamente, onde o conteúdo apresentado deveria estar de acordo com o objetivo proposto, para que o estudo pudesse ser incluído nesta revisão. Em seguida, em uma terceira etapa, realizou-se a leitura na íntegra dos artigos selecionados, construindo-se uma tabela com as principais informações de cada estudo.

Inicialmente foram identificados 123 artigos, incluindo 79 estudos encontrados na base de dados Scielo e 44 estudos no PubMed. Trinta e nove estudos foram selecionados por avaliação de elegibilidade do título e resumo com base nos critérios de inclusão, Após a etapa de elegibilidade, 5 estudos foram selecionados, sendo quatro revisões sistemáticas, um relato de caso e um ensaio clínico. 
Esta revisão integrativa abordou a seguinte questão clínica: “A sessão única na endodontia é o suficiente para um tratamento eficaz?" Para isso, estudos atuais que abordaram este assunto realizando considerações sobre o tratamento endodôntico em uma ou mais sessões clínicas foram selecionados para esta revisão integrativa.

A Figura 1 mostra um fluxograma com as etapas e a quantidade de artigos selecionados para compor esta revisão integrativa.

Figura 1. Fluxograma com processo para seleção dos artigos incluídos para esta revisão.

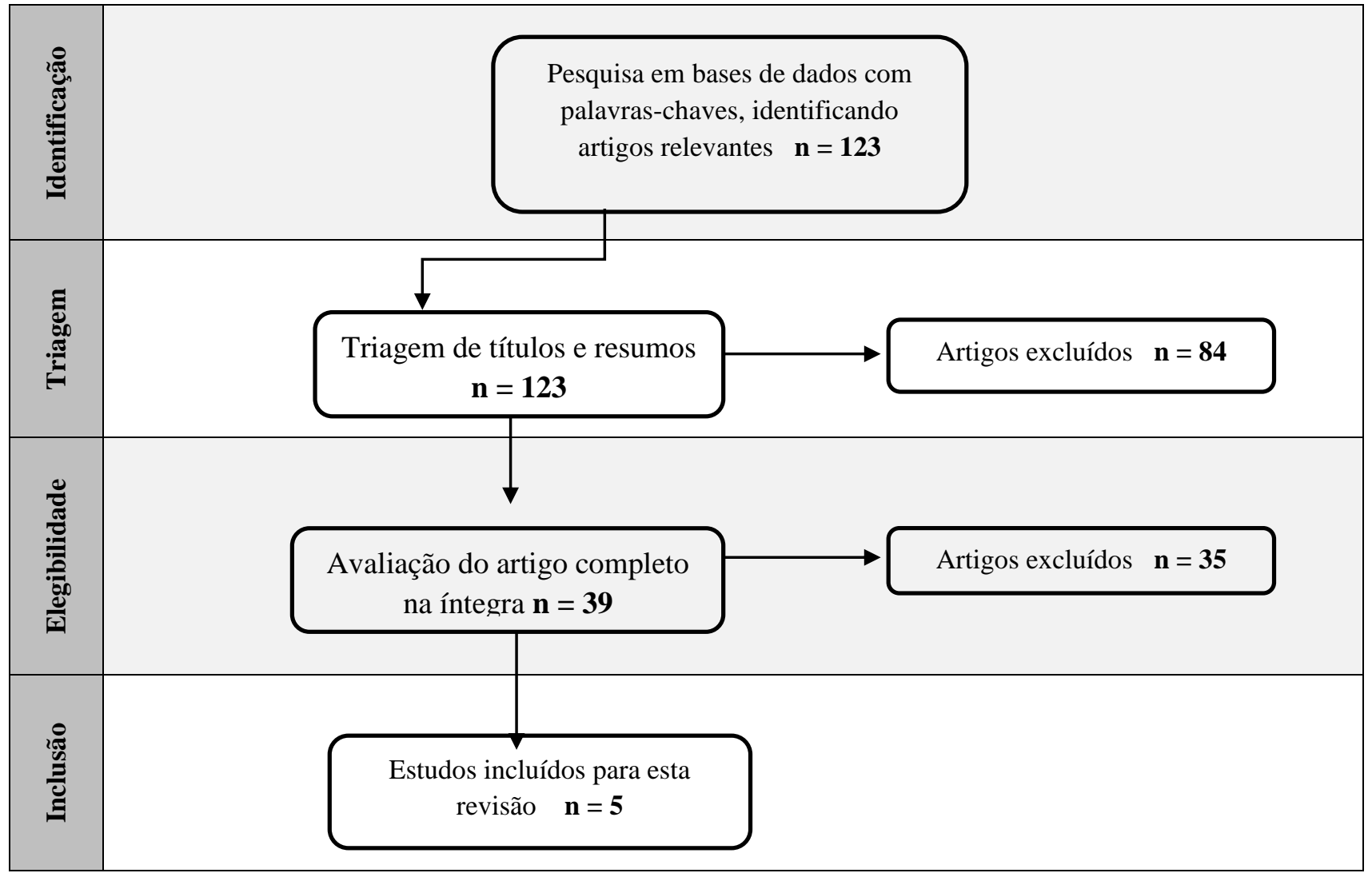

Fonte: Autores. 


\section{Resultados e Discussão}

Tabela 1 - Autor, título, tipo de estudo, objetivo, amostra e resultados dos estudos incluídos nessa revisão

\begin{tabular}{|c|c|c|c|c|c|}
\hline AUTORES & $\begin{array}{l}\text { TÍTULO DO } \\
\text { ARTIGO }\end{array}$ & $\begin{array}{l}\text { TIPO DE } \\
\text { ESTUDO }\end{array}$ & OBJETIVO & AMOSTRA & RESULTADOS \\
\hline $\begin{array}{l}\text { Nascimento, et al., } \\
2021\end{array}$ & $\begin{array}{l}\text { Comparison of the } \\
\text { efectiveness of } \\
\text { single- and multiple } \\
\text { sessions disinfection } \\
\text { protocols against } \\
\text { endotoxins in root } \\
\text { canal infections: } \\
\text { systematic review } \\
\text { and meta-analysis }\end{array}$ & $\begin{array}{l}\text { Revisão } \\
\text { sistemática e } \\
\text { metanálise }\end{array}$ & \begin{tabular}{lr}
\multicolumn{2}{l}{ Descobrir o que é } \\
mais eficaz & na \\
redução & ou \\
eliminação & da \\
endotoxina & em \\
infecções & \\
endodônticas & - \\
tratamentos & de \\
sessão única ou & oúltipla usando \\
medicamentos de \\
midróxido de cálcio
\end{tabular} & $\begin{array}{l}\text { - } 426 \text { pacientes. } \\
\text { - } 223 \text { pacientes } \\
\text { tratados em } \\
\text { sessão única. } \\
\text { - } 203 \text { pacientes } \\
\text { tratados em } \\
\text { sessão múltipla. }\end{array}$ & $\begin{array}{l}\text { A desinfecção em múltiplas sessões com } \\
\text { a colocação de Ca }(\mathrm{OH}) 2 \text { e medicações } \\
\text { intracanais são mais eficazes na redução } \\
\text { dos níveis de endotoxina das infecções } \\
\text { do canal radicular em comparação com } \\
\text { uma única sessão quando aplicados por } \\
14 \text { e } 30 \text { dias. }\end{array}$ \\
\hline $\begin{array}{l}\text { Palacios, Puche, } \\
\text { Eyzaguirre, } 2020\end{array}$ & $\begin{array}{l}\text { Tratamiento } \\
\text { endodóntico en una } \\
\text { sesión comparado } \\
\text { con múltiples } \\
\text { sesiones en pacientes } \\
\text { con dentición } \\
\text { permanente. }\end{array}$ & $\begin{array}{l}\text { Revisão } \\
\text { sistemática }\end{array}$ & \begin{tabular}{lr}
\multicolumn{2}{l}{ Avaliar a eficácia e } \\
segurança & do \\
tratamento & \\
endodôntico & em \\
uma sessão & em \\
comparação & com \\
várias sessões. &
\end{tabular} & $\begin{array}{l}\text { - } 17 \text { estudos } \\
\text { randomizados }\end{array}$ & $\begin{array}{l}\text { Tratamento endodôntico em uma sessão } \\
\text { pode resultar em pouca ou nenhuma } \\
\text { diferença na dor de curto prazo e nas } \\
\text { infecções pós-operatórias; pode reduzir } \\
\text { ligeiramente o risco de extrações } \\
\text { dentárias; pode aumentar o uso de } \\
\text { analgésicos e surtos. }\end{array}$ \\
\hline $\begin{array}{c}\text { Rossi-Fedele, } \\
\text { Kahler, } \\
\text { Venkateshbabu, } \\
2019\end{array}$ & $\begin{array}{l}\text { Limited Evidence } \\
\text { Suggests Benefits } \\
\text { Single Visit } \\
\text { Revascularization } \\
\text { Endodontic } \\
\text { Procedures - A } \\
\text { Systematic Review }\end{array}$ & $\begin{array}{l}\text { Revisão } \\
\text { sistemática }\end{array}$ & $\begin{array}{l}\text { Avaliar } \\
\text { resultados de } \\
\text { procedimentos } \\
\text { endodônticos de } \\
\text { revascularização } \\
\text { em sessão única } \\
\text { para o tratamento } \\
\text { de dentes } \\
\text { permanentes } \\
\text { imaturos com polpa } \\
\text { não vital }\end{array}$ & $\begin{array}{l}\text { - } 359 \text { estudos } \\
\text { identificados; } \\
\text { - } 7 \text { atenderam } \\
\text { aos critérios }\end{array}$ & $\begin{array}{l}\text { Procedimentos endodônticos de } \\
\text { revascularização em sessão única podem } \\
\text { ser considerados nos casos em que a } \\
\text { carga bacteriana intracanal é considerada } \\
\text { limitada, como necrose pulpar na } \\
\text { ausência de manifestações clínicas e } \\
\text { radiográficas de periodontite apical. }\end{array}$ \\
\hline Triches et al., 2018 & $\begin{array}{l}\text { Efficacy of a single } \\
\text { session protocol for } \\
\text { endodontic treatment } \\
\text { in teeth deciduous: in } \\
\text { vivo study }\end{array}$ & $\begin{array}{l}\text { Ensaio } \\
\text { Clínico }\end{array}$ & $\begin{array}{l}\text { Determinar a } \\
\text { eficácia do PQM de } \\
\text { canais radiculares } \\
\text { utilizando r o } \\
\text { protocolo de sessão } \\
\text { única em dentes } \\
\text { decíduos com } \\
\text { necrose pulpar e } \\
\text { lesão perirradicular. }\end{array}$ & - 80 crianças & $\begin{array}{l}\text { A sessão única foi capaz de reduzir o } \\
\text { conteúdo séptico em canais radiculares } \\
\text { de dentes decíduos com necrose pulpar e } \\
\text { lesão perirradicular; e, todas as bactérias } \\
\text { associadas ao tratamento de canal } \\
\text { radicular mal-sucedido, com exceção de } \\
P \text {. endodontalis, que persistiu no } \\
\text { momento da obturação do canal } \\
\text { radicular. }\end{array}$ \\
\hline $\begin{array}{l}\text { Moreira et al., } \\
\quad 2017\end{array}$ & $\begin{array}{c}\text { Endodontic } \\
\text { Treatment in Single } \\
\text { and Multiple Visits: } \\
\text { An Overview of } \\
\text { Systematic Reviews }\end{array}$ & $\begin{array}{l}\text { Revisão } \\
\text { sistemática }\end{array}$ & $\begin{array}{l}\text { Identificar todas as } \\
\text { RSs no tratamento } \\
\text { endodôntico em } \\
\text { consultas únicas e } \\
\text { múltiplas, } \\
\text { interrogar } \\
\text { qualidade } \\
\text { metodológica (risco } \\
\text { de viés) desses } \\
\text { estudos e avaliar as } \\
\text { evidências } \\
\text { disponíveis sobre as } \\
\text { melhores práticas } \\
\text { clínicas no } \\
\text { tratamento } \\
\text { endodôntico }\end{array}$ & $\begin{array}{l}\text { - } 62 \text { estudos } \\
\text { primários. } \\
\text { - } 8 \text { Incluídos. }\end{array}$ & $\begin{array}{l}\text { Menor frequência de dor nas primeiras } \\
72 \text { horas após a obturação do canal } \\
\text { radicular em sessão única. Não houve } \\
\text { diferença significativa no desconforto } \\
\text { pós-operatório nas duas abordagens. Foi } \\
\text { observada uma tendência de menor } \\
\text { desconforto para o tratamento em uma } \\
\text { única consulta. }\end{array}$ \\
\hline
\end{tabular}

Fonte: Autores (2020). 
De acordo com a literatura consultada, em relação à eficácia do tratamento endodôntico em sessão única, os 5 artigos apresentam resultados conflitantes. Em uma revisão sistemática, Rossi-Fedele, Kahler e Venkateshbabu (2019), apontaram que a abordagem endodôntica em uma única sessão apresenta resultados imprevisíveis.

Entretanto, Moreira et al (2017) em sua revisão sistemática destacam que os resultados da sessão única são semelhantes aos resultados alcançados com o tratamento tradicional de múltiplas sessões, com relação a taxa de cura, independente da condição pré-existente da polpa.

Nesta mesma revisão, os estudos analisados observaram resultados positivos superiores no tratamento de periodontite apical com a utilização da técnica em sessão única em relação a técnica em múltiplas sessões, com uma menor incidência de complicações pós-operatórias e maior eficácia na abordagem em sessão única (Moreira et al.,2017).

Acerca do sucesso do tratamento, Palácios, Puché e Eyzaguirre (2020) apontam, em uma revisão comparativa da literatura entre sessão única e múltiplas sessões, que a sessão única apresentou uma taxa de efetividade compatível com a de múltiplas sessões, porém com associação a uma maior dor pós-operatória imediata e demanda de uma maior utilização de analgésicos.

Como ponto positivo, foi visto que casos abordados com sessão única foram menos susceptíveis a complicações com necessidade de exodontia tardiamente, entretanto, foi identificada baixa evidência científica, devido a reduzida quantidade de estudos, sobre este aspecto.

De forma geral, diversos artigos analisados apresentaram ressalvas acerca da redução da carga bacteriana intracanal na abordagem endodôntica em sessão única. Rossi-Fedele, Kahler e Venkateshbabu (2019), inferem que a presença de infecção tem um impacto negativo no resultado do tratamento endodôntico, de forma que a desinfecção do sistema de canais radiculares encontra um papel chave na evolução da terapia endodôntica, fato que ganha ainda mais importância no tratamento em sessão única.

Trinches et al (2018), em seu ensaio clínico, apontam que os principais fatores para permanência bacteriana a despeito do tratamento endodôntico com medicação intracanal são: presença de cepas bacterianas resistentes ao medicamento empregado ou com capacidade neutralizante do medicamento antibacteriano pela bactéria ou seus subprodutos, bactérias localizadas em locais inacessíveis ao curativo temporário, permanência da medicação por tempo insuficiente para atingir as células bacterianas, alteração na expressão gênica bacteriana após mudança no microambiente permitindo sua sobrevivência apesar de condições desfavoráveis.

As substâncias utilizadas para abordagem do conteúdo séptico endodôntico variaram entre os estudos avaliados. De forma geral, para a irrigação do canal radicular, grandes volumes de hipoclorito de sódio $(\mathrm{NaOCl})$ foram utilizados com concentrações variando de 2,5\% e 6\%, o ácido etilenodiaminotetracético (EDTA) 17\% (REF) também foi amplamente utilizado, por sua capacidade de promover a sobrevivência das células-tronco da papila apical, reverter o efeito adverso do hipoclorito de sódio e expor a matriz dentinária para liberar o crescimento. Rossi-Fedele, Kahler e Venkateshbabu (2019), em sua revisão sistemática apontaram também a utilização de clorexidina em associação com $\mathrm{NaOCl}$ e EDTA em dois estudos.

Em sua revisão sistemática, Nascimento et al (2021) realizaram um comparação entre a abordagem em múltipla sessões (com diferença entre 7, 14 e 30 dias entre as sessões) e sessão única, com enfoque na redução dos níveis de endotoxinas do canal radicular, apontando que o uso de medicação intracanal em múltiplas sessões foi superior a sessão única apenas quando feito com diferença de 14 e 30 dias entre as sessões, sem impacto na redução das endotoxinas ao comparar a sessão única e múltiplas sessões espaçadas por apenas 7 dias.

Como contraponto, Trinches et al (2018), em um ensaio clínico, apresentaram uma redução eficaz do conteúdo séptico do canal radicular com seu protocolo de abordagem em sessão única, que incluiu a utilização de "Endo PTC" (composto por 10\% de peróxido de ureia, 15\% Tween 80 e 75\% carbowax - veículo), solução Dakin (hipoclorito de sódio 
0,5\% tamponado com bicarbonato de sódio), e Tergensol. Tais substâncias apresentaram sucesso na redução microbiana pois alteraram o microambiente do canal radicular potencializado pela ação mecânica dos instrumentais endodônticos. Endo PTC apresenta ação desinfetante, antisséptica, causando baixo grau de irritação aos tecidos e aumenta a permeabilidade da dentina, enquanto a solução de Dakin atuou como agente de limpeza e bactericida, com baixo grau de irritação nos tecidos periapicais e a utilização do Tergensol para a irrigação final removendo medicamentos residuais, diminuindo o efeito irritante.

Com relação a ocorrência de complicações, Moreira et al (2017), apontam a possibilidade de maior número de complicações com a realização de múltiplas sessões, tendo em vista fatores associados a lesões mecânicas, químicas ou microbiológicas dos tecidos periapicais. Tais fatores poderiam estar associados a extrusão de detritos contaminados, alterações na microbiota do canal radicular, preparo incompleto do canal radicular, uso de medicação intracanal, uso de alta concentração de substâncias químicas, ou a frequência constante de manipulação do canal radicular e tecidos periapicais devido ao número de sessões necessárias para completar o tratamento, levando a uma maior susceptibilidade de complicações.

A tomada de decisão sobre a técnica a ser utilizada na abordagem endodôntica, em única ou múltiplas sessões, deve levar em consideração diversos fatores, que incluem desde a experiência do operador às impressões do paciente, visando o impacto na qualidade de vida. Palácios, Puché e Eyzaguirre (2020), afirmam que o tratamento em sessão única apresenta menor custo em instrumental e pessoal e seria a primeira opção para diversos pacientes, já que demandaria menor tempo e redução na necessidade de idas ao consultório. Porém deve-se considerar o limiar de dor de cada paciente e as características do elemento dental a ser abordado.

\section{Considerações Finais}

A análise da literatura apresenta que a abordagem em sessão única apresenta resultados efetivos, entretanto, sabe-se que as técnicas são operador-dependente. Em elementos com alto índice de infecção os resultados são conflitantes, com algumas fontes apresentando resultados efetivos com o tratamento em sessão única, independente do estado do elemento abordado, e outras apresentando vantagens em uma abordagem com múltiplas sessões, quando apresenta conteúdo séptico.

Com relação as vantagens do tratamento em sessão única, o fator mais apontado nos diversos estudos é a comodidade para o paciente, com redução das idas ao consultório, e para o operador, uma redução no custo com material e tempo de atendimento. Entretanto, um fator importante a ser considerado, com conflitos na literatura sobre a percepção dolorosa do paciente, é a dor intra e pós-operatória que é similar no tratamento com sessão única e com múltiplas sessões. Dessa forma são necessários novos estudos clínicos comparando as duas técnicas, para determinar indicações claras para cada uma delas.

\section{Referências}

AlRahabi, M. K. (2017). Predictors, prevention, and management of postoperative pain associated with nonsurgical root canal treatment: A systematic review. J Taibah Univ Med Sci. 12(5):376-384. 10.1016/j.jtumed.2017.03.004.

Berutti, E., Chiandussi, G., Paolino, D. S., Scotti, N., Cantatore, G., Castellucci, A., \& Pasqualini, D. (2012). Canal shaping with WaveOne Primary reciprocating files and ProTaper system: a comparative study. J Endod. 38(4):505-9. 10.1016/j.joen.2011.12.040.

Boonchoo, K., Leelataweewud, P., Yanpiset, K., \& Jirarattanasopha, V. (2020). Simplify pulpectomy in primary molars with a single-file reciprocating system: a randomized controlled clinical trial. Clin Oral Investig. 24(8):2683-2689. 10.1007/s00784-019-03130-5.

Gavini Giulio, S. M., Caldeira, C. L., Machado, M. E. L., Freire, L. G., \& Eglecias, E. F. (2018). Nickel-titanium instruments in endodontics: a concise review of the state of the art. Braz. oral res. 32(1): 67.

Manfredi, M., Figini, L., Gagliani, M., \& Lodi, G. (2016). Single versus multiple visits for endodontic treatment of permanent teeth. Cochrane Database Syst Rev.;12(12):CD005296. 10.1002/14651858.CD005296.

Melgaço-Costa, J. L., et al. (2016). Patients' Perceptions of Endodontic Treatment as Part of Public Health Services: A Qualitative Study. Int J Environ Res Public Health. Apr 27;13(5):450. 10.3390/ijerph13050450.

Moreira, M. S., et al. (2017). Endodontic Treatment in Single and Multiple Visits: An Overview of Systematic Reviews. J Endod. Jun;43(6):864-870. 10.1016/j.joen.2017.01.021. 
Research, Society and Development, v. 10, n. 8, e45210817534, 2021

(CC BY 4.0) | ISSN 2525-3409 | DOI: http://dx.doi.org/10.33448/rsd-v10i8.17534

Nascimento, G. G., et al. (2021). Comparison of the effectiveness of single- and multiple-sessions disinfection protocols against endotoxins in root canal infections: systematic review and meta-analysis. Sci Rep. Jan 13;11(1):1226. 10.1038/s41598-020-79300-3.

Palacios, G. B., et al. (2020). Tratamiento endodóntico en una sesión comparado con múltiples sesiones en pacientes con dentición permanente. Int. $j$ interdiscip. Dent., 13(3): 217-223. http://dx.doi.org/10.4067/S2452-55882020000300217.

Rossi-Fedele, G., Kahler, B., \& Venkateshbabu, N. (2019). Limited Evidence Suggests Benefits of Single Visit Revascularization Endodontic Procedures - A Systematic Review. Braz Dent J. 30(6):527-535. 10.1590/0103-6440201902670.

Sanjay, M., Londhe, S. M., \& Sharma, S. (2019). Single-visit versus dual-visit endodontics. A comparative Study. Indian Journal of Public Health and Development. 10(7). 244 - 250. 10.598.

Schwendicke, F., \& Göstemeyer, G. (2017). Single-visit or multiple-visit root canal treatment: systematic review, meta-analysis and trial sequential analysis. BMJ Open. 7(2):e013115. 10.1136/bmjopen-2016-013115.

Souza, M. T., Silva, M. D., \& Carvalho, R. (2010). Revisão integrativa: o que é e como fazer. Einstein (São Paulo), 8(1): 102-106.

Su, Y., Wang, C., \& Ye L. (2011). Healing rate and post-obturation pain of single- versus multiple-visit endodontic treatment for infected root canals: a systematic review. J Endod 37(2):125-32. 10.1016/j.joen.2010.09.005.

Sun, C., S et al. un J, Tan M, Hu B, Gao X \& Song J. (2018). Pain after root canal treatment with different instruments: A systematic review and metaanalysis. Oral Dis. 24(6):908-919. 10.1111/odi.12854.

Tajonar, R. S. L., et al. (2017). Tratamento endodôntico em uma única sessão como única solução para uma lesão aparente do endoperium. Relato de um caso clínico. Vital Dentistry, (27), 29-34.

Triches, T. C., et al. (2018). Efficacy of a single session protocol for endodontic treatment in primary teeth: in vivo study. Eur Arch Paediatr Dent. 19(1):4755. 10.1007/s40368-018-0325-0.

Wei, X., et al. (2017). The incidence of dentinal cracks during root canal preparations with reciprocating single-file and rotary-file systems: A meta-analysis. Dent Mater J. 36(3):243-252. 10.4012/dmj.2016-208.

Wong, A. W., et al. (2014). A systematic review of nonsurgical single-visit versus multiple-visit endodontic treatment. Clin Cosmet Investig Dent. 6:45-56. 10.2147/CCIDE.S61487.

Wong, A. W., et al. (2015). Incidence of post-obturation pain after single-visit versus multiple-visit non-surgical endodontic treatments. BMC Oral Health . 15:96. 10.1186/s12903-015-0082-y 